\title{
Modos de autonomia em Serviços Residenciais Terapêuticos e sua relação com estratégias de desinstitucionalização
}

\author{
Deinstitutionalization and autonomy: outcomes from a Brazilian \\ mental health policy
}

Gabriela Andrade da Silva (https://orcid.org/0000-0002-4188-0935) ${ }^{1}$

Antônio José Costa Cardoso (https://orcid.org/0000-0002-6085-3502) ${ }^{2}$

Enrique Bessoni (https://orcid.org/0000-0003-0521-1627) ${ }^{3}$

Alexandre da Cunha Peixoto (https://orcid.org/0000-0002-3062-4207) ${ }^{1}$

Caio Rudá (https://orcid.org/0000-0002-4252-9979) ${ }^{4}$

Daniela Viana da Silva (https://orcid.org/0000-0002-1693-1374) ${ }^{1}$

Samuel Martins de Jesus Branco (https://orcid.org/0000-0003-3486-3560) ${ }^{1}$
${ }^{1}$ Centro de Formação em Ciências da Saúde, Universidade Federal do Sul da Bahia.

Praça Joana Angélica 250. 45988-058 Teixeira de Freitas BA Brasil. gabriela.silva@ufsb.edu.br ${ }^{2}$ Instituto de Humanidades, Artes e Ciências Jorge Amado, Universidade Federal do Sul da Bahia. Itabuna BA Brasil.

${ }^{3}$ Instituto de Saúde e Sociedade, Universidade Federal de São Paulo. São Paulo SP Brasil.

${ }^{4}$ Instituto de Humanidades, Artes e Ciências Paulo Freire, Universidade Federal do Sul da Bahia. Teixeira de Freitas BA Brasil.

\begin{abstract}
Therapeutic Residential Services (SRT, in Portuguese) are structures implemented in the context of the Brazilian Psychiatric Reform (BPR), which aims to support psychiatric deinstitutionalization. This paper compares residents of SRTs in two cities in Brazil, analyzing the relationship among the deinstitutionalization strategies and the different types of autonomy they produce. Nineteen individuals from two cities (referred to as Paulo Delgado - PB and Franco Basaglia - FB) participated in this study. Participant observation visits were performed, and five managers and professionals who worked at the psychosocial care networks were interviewed. Narratives were created based on the field diaries and the transcription of the interviews. All the participants raised their degree of autonomy, when compared to the time in which they lived in the psychiatric hospitals. The different ways in which SRTs are organized in both cities produced different manners of exercising autono$m y:$ in $P D$, home autonomy predominated, while in FB, autonomy in circulating throughout the territory predominated. In both cities, autonomy in managing financial resources was restricted. It was concluded that public policies for deinstitutionalization were effective, although their operationalization could be enhanced.
\end{abstract}

Key words Deinstitutionalization, Mental health, Narration, Program evaluation and health projects
Resumo Serviços Residenciais Terapêuticos (SRTs) são dispositivos implantados no âmbito da Reforma Psiquiátrica brasileira para apoiar a desinstitucionalização psiquiátrica. Esta pesquisa objetivou comparar as formas de autonomia desenvolvidas por moradores de SRTs de dois municípios da Bahia, analisando sua relação com as estratégias de desinstitucionalização construídas em cada território. Participaram 19 indivíduos dos municípios referidos pelos pseudônimos Paulo Delgado (PD) e Franco Basaglia (FB). Foram realizadas visitas para observação participante e entrevistas com cinco gestores e profissionais das redes de atenção psicossocial. Registros em diários de campo e transcrições de entrevistas subsidiaram a construção de narrativas. Todos os participantes ampliaram o grau de autonomia em relação ao período em que saíram das instituições asilares. As formas de organização dos SRTs nos dois municípios produziram diferentes modos de exercer autonomia: em PD predominou a autonomia no habitar, enquanto em FB predominou a autonomia no transitar pelo território. Em ambos, a autonomia na administração de recursos financeiros foi limitada. Consideramos que as políticas públicas para desinstitucionalização foram efetivas, embora sua operacionalização possa ser aprimorada.

Palavras-chave Desinstitucionalização, Saúde mental, Narração, Avaliação de programas e projetos de saúde 


\section{Introdução}

A Reforma Psiquiátrica Brasileira (RPB) nasceu fundada não apenas na crítica conjuntural ao subsistema nacional de saúde mental e ao caráter privatista da política de saúde do país, mas também, e principalmente, na crítica estrutural ao saber e às instituições psiquiátricas clássicas, no bojo de toda a movimentação político-social que caracterizou esta conjuntura de redemocratização ${ }^{1}$. Apresenta, assim, uma atitude crítica à exclusão de pessoas que fogem ao padrão socialmente aceito, por meio da denominação de "loucas", e de sua segregação em asilos ${ }^{2,3}$, sob a justificativa de tratar suas doenças e lidar com a periculosidade social que lhes é atribuída. Apoiando-se também no modelo italiano, cuja principal referência é Franco Basaglia ${ }^{4,5}$, a RPB compreende a loucura de forma inseparável da sociedade, a partir da polis e suas relações econômicas e sociais. Assim, concebe que não devemos buscar humanizar manicômios, mas desconstruí-los, operando a desinstitucionalização ${ }^{6}$.

Os Centros de Atenção Psicossocial (CAPS) e Serviços Residenciais Terapêuticos (SRTs), entre outros dispositivos da RPB, são um inegável avanço. Na longa história da RPB, a I Conferência Nacional de Saúde Mental marcou o movimento ao romper com sua proposta inicial, que pretendia apenas melhorar o atendimento, passando a orientar-se para a luta antimanicomial. A II Conferência Nacional de Saúde Mental, por sua vez, foi relevante pela emergência da concepção que considera as pessoas com transtornos mentais em sua existência, para além de um diagnóstico, substituindo a expressão "doença mental" por "sofrimento psíquico"-8-8. Por fim, destacamos a relevância da antipsiquiatria de Laing', ao denunciar que, por trás de teorias pretensamente científicas e de seus vocabulários metafóricos, se esconde a imposição de uma segregação radical, que afirma a existência de um padrão de ser humano que o "doente mental", especialmente o "psicótico", jamais poderá alcançar.

No entanto, atualmente, ainda se faz necessária constante reflexão sobre as práticas, visto que a trajetória da RPB também envolve cristalizações e retrocessos e nem sempre os processos de desospitalização se convertem em uma verdadeira desinstitucionalização ${ }^{7}$. Desinstitucionalizar "significa entender instituição no sentido dinâmico e necessariamente complexo das práticas e saberes que produzem determinadas formas de perceber, entender e se relacionar com os fenômenos sociais e históricos" ${ }^{\prime \prime}$ (p. 49), exigindo mudanças que se desenvolvem ao longo de três eixos principais: do encarceramento à liberdade; da tutela à autonomia; e do trabalho protegido à produção da vida ${ }^{10}$.

Sob a perspectiva basagliana, não se pode falar em desinstitucionalização se a lógica manicomial e medicalizante for reproduzida no cenário dos serviços substitutivos. Entretanto, essa característica nos coloca um paradoxo, especialmente relevante nos SRTs: o de promover a desinstitucionalização a partir da criação de novas instituições. Portanto, cabe analisar em que medida tem sido possível desconstruir a perspectiva da loucura e sua relação com a periculosidade, bem como passar da noção de tutela à de autonomia.

O objetivo deste artigo é comparar dois municípios do estado da Bahia quanto às formas de autonomia desenvolvidas por moradores de Serviços Residenciais Terapêuticos ${ }^{11}$ beneficiários do Programa De Volta Para Casa (PVC) ${ }^{12,13}$, analisando sua relação com as estratégias de desinstitucionalização construídas em cada território - análises valiosas, uma vez que artigos sobre as experiências de desinstitucionalização, frequentemente, são locais ${ }^{10,14,15}$ e não comparam territórios.

\section{De que autonomia falamos?}

A autonomia é um dos ideais da RPB, podendo inclusive ser indicativo ou sinônimo de cura, e apresenta relação indissociável com a noção de subjetividade, visto que um sujeito é necessariamente autônomo ${ }^{16}$. Trata-se de termo polissêmico, que tem sido interpretado de diferentes maneiras. No âmbito da luta antimanicomial e da desinstitucionalização, uma das definições mais aceitas é a capacidade do indivíduo gerar normas para sua vida, a partir de sua possibilidade de ampliar relações com o social. Nesse caso, é compreendida como interdependência: sendo o sujeito produto das relações sociais, ele se torna mais autônomo na medida em que estabelece o maior número de relações com pessoas e coi$\operatorname{sas}^{16,17}$. Assim, autonomia não é o contrário de dependência, mas "a capacidade do sujeito de lidar com sua rede de dependências", traduzida como "um processo de co-constituição de maior capacidade dos sujeitos de compreenderem e agirem sobre si mesmos e sobre o contexto conforme objetivos democraticamente estabelecidos"18 (p. 670). Consequentemente, nunca é absoluta, mas apresenta coeficientes e gradações ${ }^{18}$.

Entendida como necessidade de saúde, a "autonomia no modo de andar a vida" ${ }^{\prime 19}$ refere-se à 
“possibilidade de reconstrução e ressignificação dos sentidos de sua vida e de sua forma de viver, abrangendo também a luta pela satisfação de suas necessidades"20 (p. 790). O conceito diz, assim, respeito à possibilidade do sujeito fazer escolhas que melhorem sua capacidade de adaptação e sobrevivência.

Em Campina Grande, estado da Paraíba, um estudo ${ }^{10}$ que buscou identificar as representações sociais de autonomia em profissionais que atuavam em um SRT identificou núcleos de significado para "autonomia", dentre os quais destacamos: capacidade de transitar sozinho pela comunidade, presença de responsabilidade por si mesmo e administração do próprio dinheiro. Considerouse que a autonomia obtida pelos moradores não foi total, mas houve real reinserção social, percebida pela liberdade de transitar nos planos real e simbólico; e que a possibilidade de troca real e monetária no mercado propicia integração social e a possibilidade de os sujeitos com sofrimento psíquico serem percebidos como cidadãos.

Em Salvador, estado da Bahia, um estudo ${ }^{15}$ sobre o uso do PVC e do Benefício de Prestação Continuada (BPC) para a construção da autonomia dos seus beneficiários analisou interações e situações do cotidiano, destacando, como ponto favorável para o desenvolvimento da autonomia, a possibilidade de escolha dos objetos e marcas que os participantes gostariam de comprar. Porém, eles não tinham a experiência de sacar o benefício, que era administrado pelos CAPS e profissionais dos SRTs; apenas parte do valor era diretamente repassada aos beneficiários; e muitas das escolhas de produtos adquiridos ainda eram realizadas pelas equipes de referência ou cuidadoras.

Assim, embora no plano das ideias se pretenda uma gestão democrática dos SRTs, as experiências aqui referidas ${ }^{10,15}$ mostram que persiste uma relação de poder, ainda hierarquizada. Entretanto, os moradores dos SRTs não são passivos diante das estratégias da equipe de referência ou dos cuidadores, uma vez que, astutamente, criam táticas ${ }^{21}$ que configuram um outro tipo de autonomia, geralmente, percebida como "rebeldia" ou desadaptação às normas de convívio social. Portanto, para compreender o desenvolvimento da autonomia, é preciso dar voz não somente aos profissionais, mas, sobretudo, aos próprios usuários, que são sujeitos e objetos da desinstitucionalização e dispõem de táticas de tomar para si a autonomia de que, legitimamente, (ainda) não dispõem.

\section{Percurso metodológico}

O presente trabalho é um recorte de pesquisa multiterritorial e multimétodos (mista), que objetivou avaliar o impacto do PVC no processo de desinstitucionalização e reintegração social de beneficiários, e cujo percurso metodológico foi descrito por Guerrero e colaboradores $^{12}$. A pesquisa foi aprovada pelo Comitê de Ética em Pesquisa da Fiocruz Brasília pelo CAAE 57627316.4.0000.8027, sob o Parecer no 1.699.082.

Descreveremos os resultados referentes a dois municípios - cujos nomes serão substituídos por pseudônimos, ambos do estado da Bahia e de grande porte, com alta densidade populacional. O trabalho de campo incluiu observações participantes e entrevistas, realizadas por uma dupla de pesquisadores. A seleção de participantes foi intencional, buscando beneficiários do PVC contemplados desde o primeiro ano do programa (2004). Nos dois municípios pesquisados, identificamos que todos os usuários nessas condições eram moradores de SRTs - configuração que, posteriormente, descobrimos apresentar relação com o histórico dos processos de desinstitucionalização nesses territórios, uma vez que foi uma solução mais ágil para a desospitalização, diante da dificuldade de localizar famílias e mediar o retorno dos sujeitos.

No primeiro município, que chamaremos de Paulo Delgado (PD), um dos dez beneficiários do PVC selecionados se recusou a participar, de forma que a amostra foi composta por nove participantes; foram realizadas treze visitas para observação participante em cinco SRTs no período de setembro a outubro de 2017. No segundo município, que chamaremos de Franco Basaglia (FB), foram selecionados 11 beneficiários, tendo um se recusado a participar; foram realizadas 17 visitas para observação participante, entre janeiro e fevereiro de 2018.

Foram realizadas, ainda, cinco entrevistas em profundidade com atores envolvidos na gestão, assistência e acompanhamento do PVC, sendo três em Paulo Delgado e duas em Franco Basaglia. Os roteiros foram criados pela equipe de pesquisadores, e as entrevistas foram gravadas, transcritas pelo método Verbatim e enviadas para os participantes para validação. Os pesquisadores de campo relataram suas experiências de observação participante em diários de campo. Esses registros, juntamente com as transcrições das entrevistas, subsidiaram a construção de uma narrativa ${ }^{22}$ para cada um dos 19 beneficiários se- 
lecionados. Todos os nomes utilizados nas narrativas também são fictícios.

No presente trabalho, buscamos analisar as narrativas com base em categorias construídas $a$ posteriori, a partir da leitura flutuante do material e com base na literatura. Inspirados no trabalho de Macedo, Silveira e Eulálio ${ }^{10}$ e em Certeau ${ }^{21,23}$, decidimos analisar a autonomia em um sentido prático, referente ao cotidiano dos participantes, a partir de núcleos de significados que emergiram das entrevistas e da observação participante nos SRTs. Por fim, para cada categoria e na integração dos achados, assumimos três níveis de análise: o Indivíduo (cada narrativa), o Serviço Residencial Terapêutico (SRT) e o Município.

\section{Resultados e discussão}

Os participantes da presente pesquisa, conforme Quadro 1, viviam em nove SRTs. Apresentavam entre 30 e 79 anos, mas predominaram pessoas com mais de 60 . Nove pessoas $(47,4 \%)$ eram de sexo feminino. A maior parte dos participantes tinha escolaridade baixa, sendo muitos não alfabetizados. Apenas uma participante havia concluído o Ensino Médio.

Descreveremos e analisaremos, a seguir, os núcleos de significados referentes à autonomia que emergiram das entrevistas e da observação participante nas SRTs organizados em quatro categorias: habitar, transitar no território, consumir e administrar recursos financeiros e transgredir.

\section{Habitar}

A primeira característica que nos chamou a atenção nas visitas para observação participante foi visual: os espaços físicos e localizações das casas. Em PD, nos deparamos com residências amplas, bem conservadas e localizadas em bairros de classe média, em geral próximas a estabelecimentos comerciais. Em FB, por sua vez, as localizações eram variáveis, havendo SRTs em bairros centrais e turísticos, mas também em um local considerado perigoso por moradores do município. A infraestrutura dos imóveis era mais precária e usuários se queixavam de banheiro quebrado, por exemplo.

Uma característica presente em todas as residências era a personalização. Os moradores, em geral, tinham prazer de nos mostrar os objetos pessoais com os quais decoravam seus quartos: bonecas, fotografias, lençóis com desenhos de princesa ou brasões de times de futebol. Algumas paredes continham escritas ou desenhos. Essas ca- racterísticas, tão comuns em qualquer residência, naquele contexto parecia assumir outro significado: o prazer de ter um espaço a que as pessoas poderiam chamar de seu, em contraposição aos espaços sóbrios e anônimos dos manicômios, em que elementos que marcavam as identidades estavam restritos ou vedados ${ }^{3}$.

Quase todos os participantes são autossuficientes quanto aos hábitos de higiene, o que foi relatado pelas cuidadoras como uma conquista gradual desde a desospitalização. Tarefas domésticas, em todos os SRTs, são divididas entre alguns moradores e os profissionais. Em Paulo Delgado, em comparação com Franco Basaglia, era mais frequente os moradores desempenharem atividades tais como limpar a casa ou cozinhar.

A alimentação costuma ser preparada pelos profissionais ou recebida pronta. Alguns participantes relataram que preparam café, lanches ou algumas receitas de que gostam. Os participantes alimentam-se sozinhos, com exceção do SRT-G (FB), em que os profissionais montam os pratos dos moradores. O uso de utensílios perfurantes (e, portanto, potencialmente "perigosos") para comer, diferentemente do que ocorria no hospital, foi relatado como uma emancipação por uma cuidadora do SRT-F (FB): "Os residentes hoje já usam pratos e copos de vidro, não quebram mais as coisas, nem comem se não tiver garfo".

Foi evidente a diferença em relação aos papéis que cuidadoras assumiram nos dois municípios. Em Paulo Delgado, os SRTs em geral contavam com uma cuidadora por turno, que realizava vários tipos de tarefas: limpar, cozinhar, apoiar atividades de higiene pessoal e alimentação, administrar medicação, acompanhar em saídas da residência, auxiliar na administração do dinheiro, mediar conflitos, entre outras. Observou-se forte vínculo afetivo entre as cuidadoras e os moradores, que verbalizaram considerá-las membro da família e, em alguns casos, literalmente as chamavam de "mãe". Em alguns desses SRTs, havia turnos ou mesmo finais de semana em que os moradores ficavam desacompanhados. Em Franco Basaglia, por sua vez, havia um corpo de trabalhadores mais numeroso e maior divisão de tarefas - profissionais exclusivos da limpeza, da enfermagem e cuidadores. Os moradores nunca ficavam desacompanhados na residência - o que nos transmitiu a impressão de que os SRTs se aproximavam mais de um serviço do que de um lar.

Quanto às relações familiares, praticamente todos os participantes afirmaram ter os vínculos rompidos e poucos ainda têm contatos esporádicos com parentes. As famílias de origem, em 
Quadro 1. Características dos SRTs e de seus participantes.

\begin{tabular}{|c|c|c|c|}
\hline Município & SRT & Configuração do SRT & Participantes (sexo, idade, escolaridade) \\
\hline \multirow{9}{*}{$\begin{array}{l}\text { Paulo } \\
\text { Delgado } \\
(\mathrm{PD})\end{array}$} & \multirow[t]{2}{*}{ A } & \multirow{2}{*}{$\begin{array}{l}2 \text { moradores, sob os cuidados } \\
\text { de } 3 \text { profissionais, sendo } 1 \\
\text { pago pela prefeitura e } 2 \text { pelos } \\
\text { moradores }\end{array}$} & Antonio (masculino, 76, alfabetizado) \\
\hline & & & José (masculino, 63, alfabetizado) \\
\hline & \multirow[t]{3}{*}{ B } & \multirow{3}{*}{$\begin{array}{l}3 \text { moradoras e } 2 \text { moradores, } \\
2 \text { cuidadoras pagas pela } \\
\text { prefeitura }\end{array}$} & Márcia (feminino, 46, não alfabetizada) \\
\hline & & & Camila (feminino, 63, magistério) \\
\hline & & & Manoel (masculino, 59, não alfabetizado) \\
\hline & \multirow[t]{2}{*}{$\mathrm{C}$} & \multirow{2}{*}{$\begin{array}{l}3 \text { moradoras e } 1 \text { morador, } \\
2 \text { cuidadoras pagas pela } \\
\text { prefeitura }\end{array}$} & Gilmara (feminino, 51, não alfabetizada) \\
\hline & & & Dora (feminino, 59, ensino fundamental II completo) \\
\hline & $\mathrm{D}$ & $\begin{array}{l}6 \text { moradoras e } 3 \text { cuidadoras } \\
\text { pagas pela prefeitura }\end{array}$ & Valentina (feminino, 71, alfabetizada) \\
\hline & $\mathrm{E}$ & $\begin{array}{l}5 \text { moradores e } 3 \text { moradoras, } \\
2 \text { cuidadoras pagas pela } \\
\text { prefeitura }\end{array}$ & Margarida (feminino, 71, não alfabetizada) \\
\hline \multirow{10}{*}{$\begin{array}{l}\text { Franco } \\
\text { Basaglia (FB) }\end{array}$} & \multirow[t]{4}{*}{$\mathrm{F}$} & \multirow{4}{*}{$\begin{array}{l}6 \text { moradores e uma moradora, } \\
12 \text { profissionais }\end{array}$} & Helena (feminino, 56, ensino fundamental II) \\
\hline & & & Marcos (masculino, 79, não alfabetizado) \\
\hline & & & Arthur (masculino, 57, escolaridade desconhecida) \\
\hline & & & $\begin{array}{l}\text { Vicente (masculino, cerca de 70, escolaridade } \\
\text { desconhecida) }\end{array}$ \\
\hline & \multirow[t]{3}{*}{ G } & \multirow{3}{*}{$\begin{array}{l}9 \text { moradores (todos oriundos } \\
\text { de um Hospital de Custódia), } 8 \\
\text { profissionais }\end{array}$} & Moisés (masculino, 77, não alfabetizado) \\
\hline & & & $\begin{array}{l}\text { Lucas (masculino, 57, escolaridade desconhecida - } \\
\text { sabe-se que estudou e foi servidor público) }\end{array}$ \\
\hline & & & $\begin{array}{l}\text { Pedro (masculino, } 73 \text {, voltou a estudar após ir para o } \\
\text { SRT, mas parou) }\end{array}$ \\
\hline & \multirow[t]{2}{*}{$\mathrm{H}$} & \multirow[t]{2}{*}{6 moradoras, 15 profissionais } & $\begin{array}{l}\text { Jurema (feminino, idade desconhecida - aparenta } \\
\text { mais de } 40 \text { anos, voltou a estudar após ir para o SRT) }\end{array}$ \\
\hline & & & $\begin{array}{l}\text { Amélia (feminino, idade desconhecida - aparenta } \\
\text { entre } 40 \text { e } 45 \text { anos, ensino fundamental I completo) }\end{array}$ \\
\hline & I & 7 moradores, 15 profissionais & $\begin{array}{l}\text { Anderson (masculino, 30, voltou a estudar após ir } \\
\text { para o SRT) }\end{array}$ \\
\hline
\end{tabular}

Fonte: Autores.

geral, têm paradeiro desconhecido, são falecidas ou não desejam manter comunicação, sendo frequente o sentimento de abandono, como constatou pesquisa anterior ${ }^{10}$. No entanto, muitos dos beneficiários consideram que os moradores e cuidadores do SRT são sua atual família, e usam o dinheiro do PVC para presenteá-los, fazer festas e passeios, nos quais intensificam essas relações.

Analisando as duas configurações, observamos maior autonomia em Paulo Delgado que em Franco Basaglia nos modos de habitar, caracterizada por maior participação nas tarefas domésticas, possibilidade de permanecer na residência sem a presença de funcionários e de os moradores escolherem com quem queriam morar, auto- rizando ou impedindo a entrada de novos colegas - o que não era possibilitado em Franco Basaglia.

\section{Transitar no território}

Quanto a esta categoria - transitar no território -, inversamente, percebemos uma autonomia maior em Franco Basaglia, em comparação a Paulo Delgado. Naquele município, percebe-se integração dos moradores dos SRTs com seus territórios e comunidades. São conhecidos nos seus bairros, interagindo com comerciantes e vizinhos; alguns usam transporte público desacompanhados e mantêm rotinas diárias de deslocamento, como ir à escola ou à academia - atividades que 
nenhum participante de Paulo Delgado realizava. Observamos que muitos deles entravam e saíam com frequência de suas residências e, em geral, não havia restrição em relação a esses passeios, embora algumas regras tenham sido estabelecidas. Exemplificamos com trecho da narrativa sobre Vicente (SRT-F, FB):

Vicente entrava e saía com tanta frequência, que por vezes nem nos dávamos conta. Tem uma vida bastante movimentada na comunidade. Costuma ir à clínica [nome omitido] e à Defensoria Pública, onde toma café e conversa com os funcionários. Toma café preto com açúcar em uma barraca que fica na rua da RT. Semanalmente, há oito anos, um vizinho the dá oitenta reais, que Vicente faz questão de ir buscar pessoalmente. Apesar da liberdade de ir e vir, há um acordo entre os usuários e a equipe para que os moradores evitem sair no período noturno. Além disso, Amélia [cuidadora] lembra a Vicente que ele deverá retornar para tomar sua medicação às 15 horas.

Em Paulo Delgado, por sua vez, nenhum dos participantes usa o transporte público. Quando desacompanhados, a maioria sai apenas para locais próximos às suas residências, a pé, para fazer pequenas compras, conversar com vizinhos ou ir ao CAPS, por exemplo. Para percursos mais longos, chamam sempre o mesmo taxista, que já os conhece, e não saem de casa se ele não estiver disponível. Foi frequente o relato de que antigamente eram mais autônomos para transitar pela cidade, inclusive de ônibus e realizando viagens para outros municípios desacompanhados, mas com o passar dos anos, ficaram limitados pela perda de mobilidade física decorrente do envelhecimento.

As cuidadoras de Paulo Delgado justificaram as restrições ao trânsito dos moradores como gestos de cuidado, em decorrência da violência urbana, por risco de se perder ou por condições físicas que reduzem a mobilidade. Relataram episódios de quedas, roubo e de Manoel (SRT-B, $\mathrm{PD})$, que certa vez, desapareceu pelo período de um mês, após o qual foi encontrado "andando na BR" (rodovia). Em Franco Basaglia, ouvimos relatos semelhantes, mas que nem sempre geraram restrições às saídas. Helena (SRT-F, FB) certa vez se perdeu e conseguiu retornar para a residência apenas às três horas da manhã, deixando os funcionários bastante apreensivos; ainda assim, não está proibida de sair novamente. No SRT-G, o bairro é considerado perigoso, por ter uma alta taxa de crimes, e a maior parte dos moradores não sai de casa. Lucas é uma exceção, pois passeia pelo bairro e o considera "tranquilo", apesar de já ter sofrido tentativa de assalto e de mencionar tiroteios em decorrência do tráfico.

\section{Consumir e administrar recursos financeiros}

Conforme percurso metodológico adotado, todos os participantes recebiam o PVC. Alguns moradores contavam com outros recursos, tais como aposentadoria ou BPC, mas nenhum realizava atividade remunerada. De forma geral, a possibilidade de ter acesso direto ao dinheiro impulsionou a relação com o território: compram, vendem, emprestam, têm crédito na praça e, dessa maneira, vão estabelecendo trocas e contratualidades, passando a se reconhecer e a serem reconhecidos como cidadãos ${ }^{13,15}$. Essas relações com o território mediadas pelo dinheiro foram construídas ao longo do tempo:

De acordo com a cuidadora Amélia, "no hospital eles não tinham acesso a dinheiro. Inicialmente, eles pegavam o dinheiro, rasgavam, jogavam fora. Eles não sabiam o que era dinheiro". Eles aprenderam o que é o dinheiro e, "se fosse para retirar deles isso agora, seria muito difícil". É perceptível que os residentes já sabem o que querem: "eles vão ao mercado, sabem o valor das coisas, reconheceme diferenciam as notas". (SRT-F, FB)

Os pequenos bens adquiridos pelos próprios beneficiários expressaram singularidades e desejos que permitem o resgate e a consolidação de sua identidade. Conforme relatou uma cuidadora do SRT-C (Paulo Delgado): "eles gostam de gastar, sentem prazer; a gente quando tem dinheiro gosta de gastar e com eles não é diferente". Frequentemente em nossas visitas, participantes mostravam as marcas dos produtos que gostavam de comprar, como por exemplo: o creme dental, o absorvente íntimo ou o barbeador. Corroborando pesquisas anteriores ${ }^{15}$, as possibilidades de escolha presentes nos detalhes do dia a dia se mostraram produtoras de autonomia e construtoras de subjetividades no processo de desinstitucionalização. Esse olhar para as banalidades do cotidiano é importante por nos levar a compreender o papel do PVC na construção da autonomia.

Entretanto, a autonomia foi limitada pela forma de administrar o dinheiro dos participantes de ambos os municípios, centralizando-o aos cuidados de algum profissional do CAPS e entregando aos beneficiários uma parcela, em geral com periodicidade semanal - diferentemente do que foi determinado pela Lei $10.708^{24}$, que prevê pagamento diretamente aos beneficiários. $\mathrm{O}$ fato de não poderem sacar o benefício contribuiu, em 
alguns casos, para fantasias sobre o quanto realmente recebem e o que poderiam fazer com esse dinheiro ${ }^{15} \mathrm{e}$ a verbalização de que estariam sendo roubados ou privados de sua liberdade.

Em alguns SRTs, cuidadoras ou profissionais de referência tomaram para si até mesmo a escolha de roupas e itens de higiene pessoal - corroborando pesquisa anterior ${ }^{15}$-, prática que anula parte da função do PVC, que busca construir autonomia pelo resgate da subjetividade. Porém, dentro do mesmo SRT, há diferenças no nível de autonomia por morador. Antônio (SRT-A, PD), por exemplo, é o único beneficiário que tem em mãos seu cartão do PVC e quando, devido à sua restrição de mobilidade, precisa de ajuda da cuidadora para fazer compras ou pagamentos, pedelhe todos os recibos. Logo, o nível de autonomia na administração dos recursos financeiros variou, sobretudo, de acordo com fatores individuais e da equipe de referência dos SRTs.

Nos dois municípios, foram relatados históricos semelhantes: no início do programa, os cuidadores dos SRTs administravam os benefícios junto com cada usuário, mas isso gerou sobrecarga, levando essa atividade a ser executada pelos CAPS. Essa questão tem sido tensionada pelas equipes, que reconhecem que o ideal seria que cada beneficiário administrasse seu dinheiro, mas não conseguiram operacionalizar essa proposta no cotidiano. Na fala de uma das cuidadoras: "o dinheiro não deveria ser gerenciado pela técnica de enfermagem. Por mais que ela traga recibos e notas fiscais, não dá liberdade para os beneficiários".

Algumas das razões apontadas para a centralização da administração dos recursos financeiros no CAPS são operacionais, enquanto outras passam por percepções e valores da equipe de referência. As justificativas foram: 1. limitações físicas ou mentais que impedem ou dificultam a realização das tarefas necessárias; 2 . medida de segurança financeira, criando-se uma reserva para demandas de urgência; 3 . custeio de certos itens considerados fundamentais (como medicação de alto custo) ou despesas fixas demandadas pelos usuários, como TV por assinatura; 4. evitar o mau uso do dinheiro, entendido como: comprar coisas consideradas pelos profissionais como fúteis ou destruir as notas de dinheiro; 5 . evitar riscos e prejuízos à saúde, como comprar bebida alcoólica ou itens perigosos (ex.: facas) ou ser explorados por pessoas mal-intencionadas; 6 . a prática de deixar a administração dos recursos inteiramente para o usuário já foi tentada, mas ocorreram diversos problemas.

\section{Transgredir}

No dicionário - vide https://www.dicio.com. br/ -, o verbete transgredir é descrito como "não cumprir, não observar (ordem, lei, regulamento etc.); infringir, violar.", mas também como "ir além de; atravessar". Falaremos nesta categoria de análise das táticas que os participantes criaram em contraposição às estratégias estabelecidas nos $\mathrm{SRTs}^{21}$, indo além da autonomia que lhes é concedida e produzindo para si um pouco mais de liberdade.

Conforme já mencionamos, uma das principais interdições apresentadas pelos SRTs é a administração integral do próprio dinheiro. Considerando pequena a fração que efetivamente recebem, alguns beneficiários criaram táticas para ampliar o acesso a recursos. O exemplo mais frequente foi o hábito - reprovado pela equipe de pedir dinheiro. Embora por vezes considerado ato mecânico, herdado da instituição manicomial, sugerimos que é mais provável que decorra de uma real insatisfação com o montante recebido e com a impossibilidade de gerir os próprios recursos financeiros ${ }^{25}$, que foi expressada por alguns participantes.

Algumas relações entre os moradores dos SRTs também são mediadas pelo dinheiro. Antônio (SRT-A, PD) disse que o dinheiro é importante para namorar; suas namoradas, também moradoras de SRTs, costumavam trocar relações sexuais por dinheiro, que ele oferecia de bom grado. No SRT-G (FB), por sua vez, existe uma economia interna: dois moradores atuam como agiotas, emprestando a juros ou vendendo cigarro a preços maiores que os praticados na região; outro morador, na busca por ampliar seu poder de compra, endividou-se ao tomar empréstimos dos colegas. Emprestar ou endividar-se são escolhas possíveis para quem não tem diagnóstico de "louco", mas dentro do SRT, essa transgressão levou a intervenção da equipe de referência.

Observamos, ainda, transgressões nas regras da casa, como por exemplo, na restrição de consumo de cigarro e álcool. Na perspectiva da redução de danos, algumas cuidadoras limitaram a quantidade de cigarros por dia, regra que alguns moradores contestavam ou burlavam, fumando escondidos. Foram relatadas intervenções de profissionais do CAPS junto a donos de bar, para que não vendessem bebidas alcoólicas aos moradores dos SRTs. Um deles concordou em não vender a Manoel (SRT-B, PD), mas os clientes continuaram a comprar bebida para ele, levando a equipe de referência a decidir por uma mudan- 
ça de residência. No SRT-G (FB), curiosamente, foi improvisado um pequeno elevador em uma brecha aberta na tela de uma das janelas, por onde os moradores enviam dinheiro e recebem produtos (em geral, guloseimas, cigarros e bebidas alcoólicas) da venda ao lado; o dono, mesmo quando abordado por técnicos de referência do CAPS, não concordou em assumir o papel regulatório, afirmando que é um comerciante.

No SRT-A (PD), observamos um interessante ponto de conflito acerca de cuidados com a horta. A cuidadora estimulava os dois moradores a regar as plantas, afirmando que seria uma atividade saudável, mas José recusava, justificando que a horta não é dele e exigindo remuneração por esse trabalho; aliás, conforme relatou, temia que o pagamento do PVC fosse interrompido "pelo presidente", uma vez que é proibido seu recebimento por pessoas que trabalham. Ao analisar essa negativa, lembramos que para além das boas intenções da equipe, a ideia de que o trabalho é terapêutico (laborterapia) e não precisa ser remunerado também é uma característica de instituições totais, como o manicômio ${ }^{3}$. Uma vez que a iniciativa de construir a horta não partiu de José, a resistência em envolver-se nessa atividade é uma defesa de sua autonomia.

\section{Modos de autonomia e suas relações com as configurações das instituições}

Para todos os participantes desta pesquisa, em todos os SRTs e em ambos os municípios, os níveis de autonomia atuais são sempre superiores, quando comparados aos relatados por eles próprios e pelas cuidadoras e profissionais de referência quando saíram das instituições asilares. Essa autonomia não se caracteriza como independência total, mas pela redução da dependência de uma única instituição - o hospital psiquiátrico - e a construção da interdependência em relação a diversas pessoas e dispositivos da rede, no território ${ }^{16-18}$.

Em todos os casos analisados, os indivíduos se tornaram mais autônomos no modo de andar a vida ${ }^{19}$ na medida em que estabeleceram maior número de relações com pessoas e coisas ${ }^{16,17} \mathrm{e}$ foram se tornando capazes de lidar com essa rede maior e mais complexa de dependências. A possibilidade dos sujeitos fazerem escolhas ampliou a possibilidade de reconstruir e ressignificar os sentidos de sua vida e, num ciclo virtuoso, ampliou a possibilidade de fazer escolhas melhores, porque melhor adaptadas, e agir sobre si mesmos e sobre o contexto.
De acordo com o percurso metodológico adotado (qualitativo, com amostra intencional), o objetivo do trabalho não é comparar, quantitativamente, o nível de autonomia por usuário, município ou SRT. As análises nos permitiram observar que as formas de organização dos SRTs em ambos os municípios produziram diferentes modos de exercer essa autonomia: de maneira geral, entendemos que em Paulo Delgado predominou uma autonomia no habitar, enquanto em Franco Basaglia predominou uma autonomia no transitar.

De acordo com Certeau ${ }^{23}$, as práticas elementares do cotidiano são o nível possível de inventividade do cidadão comum. Por exemplo, ao cozinhar, o sujeito estabelece uma relação com a tradição, expressa nas receitas, combinações de alimentos e etiquetas e concatena uma série de comportamentos complexos: escolher ingredientes, comparar preços, planejar-se cronologicamente e espacialmente na cozinha, servir, descartar, arrumar, limpar, conservar, readaptar-se às adversidades (como um ingrediente derramado). Porém, essa atividade foi observada em poucos SRTs, todos eles no município de Paulo Delgado. Nos demais, é mais frequente que os moradores recebam a comida pronta de um restaurante, ou preparada por cuidadoras.

A liberdade de transitar, por sua vez, promove o contato entre o espaço público e o privado ${ }^{23}$, de forma que ali se apresenta a tática no "lugar do outro". O cidadão estabelece trajetórias baseadas no conhecimento dos lugares, nas relações com a vizinhança e com comerciantes; expressa comportamentos visíveis no espaço social da rua, traduzidos pelo vestuário e códigos de cortesia, ritmo de andar, valorização ou evitação de determinado espaço público. Assim, o bairro, segundo Certeau ${ }^{23}$, seria a privatização progressiva do espaço público, em uma solução de continuidade entre o que é mais íntimo (espaço privado da residência) e o que é mais desconhecido (a cidade). A autonomia no transitar foi mais presente no município de Franco Basaglia, onde os participantes estavam, em geral, bastante integrados aos seus bairros.

É importante considerar que a avaliação do que está em jogo muda dependendo do ponto de vista a partir do qual se olha o mundo, e que a construção das narrativas e das vivências se dá na articulação de uma série de dimensões, tradições, produções científicas, costumes e novas formas de administração pública que estão presentes na vida dessas pessoas, atuando como pressões e limites. Assim, é fundamental saber qual é a fun- 
ção desempenhada pelo trabalho técnico nessas instituições, por quais relações de poder esse trabalho é atravessado, quais são os ecos do seu trabalho, o que faz falar e o que faz calar, isto é, em que bases se estabelece a relação cuidador/ cuidado na vida cotidiana dessas pessoas.

Em Paulo Delgado, os SRTs contavam com poucas cuidadoras, que assumiram uma função materna, a qual inclui um senso de proteção; assim, notamos a tendência de reduzir a liberdade de trânsito, sob a justificativa de evitar correr riscos. Em Franco Basaglia, por sua vez, os moradores se encontravam em casas com infraestrutura mais precária e com número maior de profissionais, nunca ficavam desacompanhados nas residências e realizavam menos atividades domésticas. Nesse município, em lares menos familiares e convidativos, tinham aberta a possibilidade de transitar e inseriram-se no território e na comunidade, apropriando-se do espaço público.

Por fim, devemos analisar a autonomia no consumir. Ao não criar seus próprios bens, consumidores utilizam aqueles que lhes são impostos, mas não obedecem necessariamente ao repertório e procedem a operações próprias, marcadas pela astúcia ${ }^{21}$. Assim, autonomia também passa pelas escolhas ao consumir, que têm sido viabilizadas pelo PVC. O benefício tem possibilitado transitar nos planos real e simbólico, ampliando as contratualidades por meio das trocas monetárias ${ }^{10}$. Porém, para a maior parte dos usuários, em ambos os municípios, persiste a centralização da administração do dinheiro nos CAPS, ainda que seja tensionada no cotidiano das equipes de saúde mental, bem como pela postura crítica de alguns dos beneficiários.

Nesse sentido, vale lembrar que não é mera coincidência a infantilização que sofrem as pessoas consideradas loucas; recaem sobre elas noções de incapacidade, de incompletude, de fragilidade. Loucura e infância se parecem em muitos aspectos para os olhos da ciência psiquiátrica ou psicológica quando não há compromisso com a crítica, de forma que as diferenças e singularidades são transformadas em desigualdades, das quais surgem novas técnicas e teorias, construídas em um ambiente hierarquizado, que visam à manutenção deste status quo.

\section{Considerações finais}

Consideramos o estudo relevante por sua aplicação à prática profissional, ao mostrar as diferentes formas de autonomia e suas associações com os modos de cuidados praticados nos SRTs, bem como a importância do PVC para a reconstrução da subjetividade dos beneficiários. Idealmente, as liberdades no habitar, transitar e consumir são igualmente relevantes. Conforme afirmaram Moreira e Andrade ${ }^{7}$ ao analisar SRTs, "a questão central é o viver na cidade ou conquistar o exercício cidadão, necessitando para tal, um espaço habitacional próprio, que se configure como um lar e não um local de tratamento" (p. 51). Logo, tais condições deveriam ser objeto de frequentes reflexões e discussões com as equipes de referência, cuidadoras e usuários, objetivando que os sujeitos caminhem, progressivamente, na direção de maior autonomia. Sugerimos, ainda, situar a independência na administração do PVC, com a posse do cartão por cada beneficiário, como horizonte dos projetos terapêuticos singulares, com constante avaliação do grau de autonomia alcançado no gerenciamento desses recursos. Do ponto de vista científico, futuramente, seria relevante estudar as formas e o grau de autonomia alcançados entre beneficiários do PVC que vivem fora dos SRTs, bem como dos egressos de instituições psiquiátricas que não dispõem desse benefício.

\section{Colaboradores}

GA Silva e AJC Cardoso participaram ativamente da concepção do trabalho, delineamento da pesquisa, análise e interpretação dos dados, redação do manuscrito e coordenação da pesquisa. Aprovaram a versão final a ser publicada e responsabilizam-se pelo conteúdo. E Bessoni participou ativamente da concepção do trabalho, delineamento da pesquisa, análise e interpretação dos dados, revisão crítica do conteúdo do texto e coordenação da pesquisa. Aprovou a versão final a ser publicada e responsabiliza-se pelo conteúdo. AC Peixoto e C Rudá participaram ativamente da análise e interpretação dos dados, redação do manuscrito e revisão crítica do conteúdo do texto. Aprovaram a versão final a ser publicada e responsabilizamse pelo conteúdo. DV Silva e SMJ Branco participaram ativamente da coleta de dados, análise e interpretação dos dados e revisão crítica do conteúdo do texto. Aprovaram a versão final a ser publicada e responsabilizam-se pelo conteúdo. 


\section{Referências}

1. Amarante P. Uma aventura no manicômio: a trajetória de Franco Basaglia. Hist Cienc Saude-Manguinhos 1994; 1(1):61-77.

2. Foucault M. História da loucura. São Paulo: Editora Perspectiva; 1972.

3. Goffman E. Manicômios, prisões e conventos. São Paulo: Editora Perspectiva; 1974.

4. Basaglia F. A Psiquiatria alternativa: contra o pessimismo da razão, o otimismo da prática: as conferências no Brasil. São Paulo: Editora Brasil Debates; 1979.

5. Basaglia F. A instituição negada: Relato de um hospital psiquiátrico. 3a ed. São Paulo: Graal; 1985.

6. Amarante P. Loucos pela vida: a trajetória da reforma psiquiátrica no Brasil. 2a ed. Rio de Janeiro: Editora Fiocruz; 1995.

7. Moreira MIB, Andrade AN. Habitar a cidade: análise de Serviços Residenciais Terapêuticos. Psicol Soc 2007; 19(3):46-54.

8. Brasil. Ministério da Saúde (MS). Coordenação de Saúde Mental. Relatório final da $2^{a}$ Conferência Nacional de Saúde Mental. Brasília: MS, Secretaria de Assistência à Saúde, Departamento de Assistência e Promoção à Saúde, Coordenação de Saúde Mental; 1994.

9. Laing RD. O eu dividido: estudo existencial da sanidade e da loucura. Petrópolis: Editora Vozes; 1987.

10. Macedo JM, Siveira MFA, Eulálio MC. Com a palavra, os profissionais: estudo das representações sociais da autonomia dos moradores da "Casa Azul". In: Silveira MFA, Santos Junior HPdO, organizadores. Residências terapêuticas: pesquisa e prática nos processos de desinstitucionalização. Campina Grande: EDUEPB; 2011. Edição do Kindle.

11. Guerrero AVP, Bessoni EA, Cardoso AJC, Vaz BC, Braga-Campos FC, Badaró MIM. O Programa de Volta para Casa na vida cotidiana dos seus beneficiários. Saude Soc 2019; 28(3):11-20.

12. Bessoni E, Capistrano A, Silva G, Koosah J, Cruz K, Lucena M. Narrativas e sentidos do Programa de Volta para Casa: voltamos, e daí?. Saude Soc 2019; 28(3):4053.

13. Brasil. Ministério da Saúde (MS). Gabinete do Ministro. Portaria no 106, de 11 de fevereiro de 2000. Institui os Serviços Residenciais Terapêuticos. Diário Oficial da União, Brasília, DF, 24 fev. 2000. p. 23.

14. Fassheber VB, Vidal CEL. Da tutela à autonomia: narrativas e construções do cotidiano em uma residência terapêutica. Psicol Cienc Prof 2007; 27(2):194-207.

15. Lima SS, Brasil SA. Do Programa de Volta para Casa à conquista da autonomia: percursos necessários para o real processo de desinstitucionalização. Physis 2014; 24(1):67-88

16. Leal EM. Clínica e Subjetividade: a questão da autonomia na Reforma Psiquiátrica Brasileira. In: Figueiredo AC, Cavalcanti MT, organizadores. A Reforma Psiquiátrica e os desafios da desinstitucionalização: contribuições à III Conferência Nacional de Saúde Mental. Rio de Janeiro: Edições CUCA - IPUB/UFRJ; 2001, 1. p. 69-83.
17. Kinoshita RT. Contratualidade e reabilitação psicossocial. In: Pitta A, organizador. Reabilitação psicossocial no Brasil. São Paulo: Hucitec; 1996. p. 55-59.

18. Onocko Campos RT, Campos GWdS. Co-construção de autonomia: o sujeito em questão. In: Campos GWS, Minayo MCS, Akerman M, Drumond Júnior M, Carvalho YM. Tratado de Saúde Coletiva. Editora Hucitec/Fiocruz; 2006, p. 669-688.

19. Cecilio LCdO. As necessidades de saúde como conceito estruturante na luta pela integralidade e equidade na atenção em saúde. In. Pinheiro R, Mattos RAd. Os sentidos da integralidade na atenção e no cuidado à saúde. Rio de Janeiro: IMS ABRASCO; 2001. p.113126.

20. Santos PT, Bertolozzi MR, Hino P. Necessidades de saúde na atenção primária: percepção de profissionais que atuam na educação permanente. Acta Paul Enferm 2010; 23(6):188-195.

21. Certeau M. A invenção do cotidiano: 1. Artes de fazer. Petrópolis: Vozes; 1994.

22. Koosah J, Moreira MIB, Braga-Campos FC. Construindo histórias em tessitura lenta: desinstitucionalização e narrativas em pesquisa. Saude Soc 2019; 28(3):29-39.

23. Certeau M. A invenção do cotidiano: 2. Morar, cozinhar. $7^{\mathrm{a}}$ ed. Petrópolis: Vozes; 2008.

24. Brasil. Lei $\mathrm{N}^{\circ} 10.708$, de 31 de julho de 2003. Institui o auxílio-reabilitação psicossocial para pacientes acometidos de transtornos mentais egressos de internações. Diário Oficial da União, Brasília, DF, 31 jul. 2003. p. 3.

25. Araújo AL. Doentes, pobres ou mendigos? A prática de pedir esmola na Casa de Saúde de S. José [dissertação]. Braga, Portugal: Universidade Católica Portuguesa; 2015.

Artigo apresentado em 30/10/2020

Aprovado em 16/10/2021

Versão final apresentada em 18/10/2021

Editores-chefes: Romeu Gomes, Antônio Augusto Moura da Silva 